\title{
BUFFALO BERRY CROP IS RIPE FOR THE PICKIN'
}

Taylor Steeves, Saskatoon, SK

\section{This article originally appeared in the Saskatoon Sun.}

The late fall, after a few hard frosts, is the time to harvest buffalo berries (Sheperdia canadensis). The bright red fruits have a distinctly acid flavour, which is much improved by exposure to frost and, harvested any time from now on, they will produce a tangy, slightly spicy jelly to enhance meat or fish dishes. They also can be used to make an interesting if somewhat unusual wine.

The buffalo berry has a wide distribution on the Prairies of western North America and the Saskatoon area is just about at the northern edge of its natural range. Nonetheless it flourishes here and dense thickets with a greyish cast to the foliage are a common sight. The grey colour results from the presence of umbrella-like surface hairs that are among the most complex found on plants.

They are worth looking at closely with a good hand lens or microscope. Although the plant must be well adapted to withstand our periodic prolonged droughts, it does have a preference for locations where it can reach a reliable water supply, such as along water courses or where the water table is high. In fact, long-time prairie residents report that it has been used as an indicator of suitable spots to dig for water.
The dense thickets are the result of a vigorous system of vegetative reproduction. This is accomplished by way of roots, which give rise to shoot buds and thus establish new stems on the periphery of existing clumps. This explains how the thickets increase in size, but it does not account for the establishment of new ones. Although fruits are produced abundantly and the seeds are viable, it is extremely rare to find a seedling.

The absence of seedlings, however, is not unique to buffalo berry and is a common phenomenon among prairie woody plants. The development of clumps vegetatively as extensions of individual plants explains why some regularly bear fruit while others never do. Buffalo berry is one of those species which has separate staminate (male) and pistillate (female) individuals and consequently entire clumps will be one or the other. Only the female plants can be expected to produce fruit.

Another feature of the roots is worth noting. Buffalo berry is one of the plant species which form root nodules in association with microorganisms and these are able to fix nitrogen, certainly an advantage on prairie soils.

One distinctly unattractive feature of the buffalo kerry is the formation of particularly brutal thorns, which are certainly a deterrent to berry 
pickers (and probably to browsing animals as well).

These thorns are modified side branches of main shoots which grow for awhile before their tips become hard and pointed. They in turn usually bear branch thorns, adding to the discomfort they can cause. There is a great deal of interest at present in the possibility of turning some of our native fruit plants into cultivated crops and the Saskatoon berry success story shows that it can be done. The buffalo berry is a good candidate for domestication but, if it is to be tamed, the plant breeders (or perhaps genetic engineers) will have to do something about those thorns.

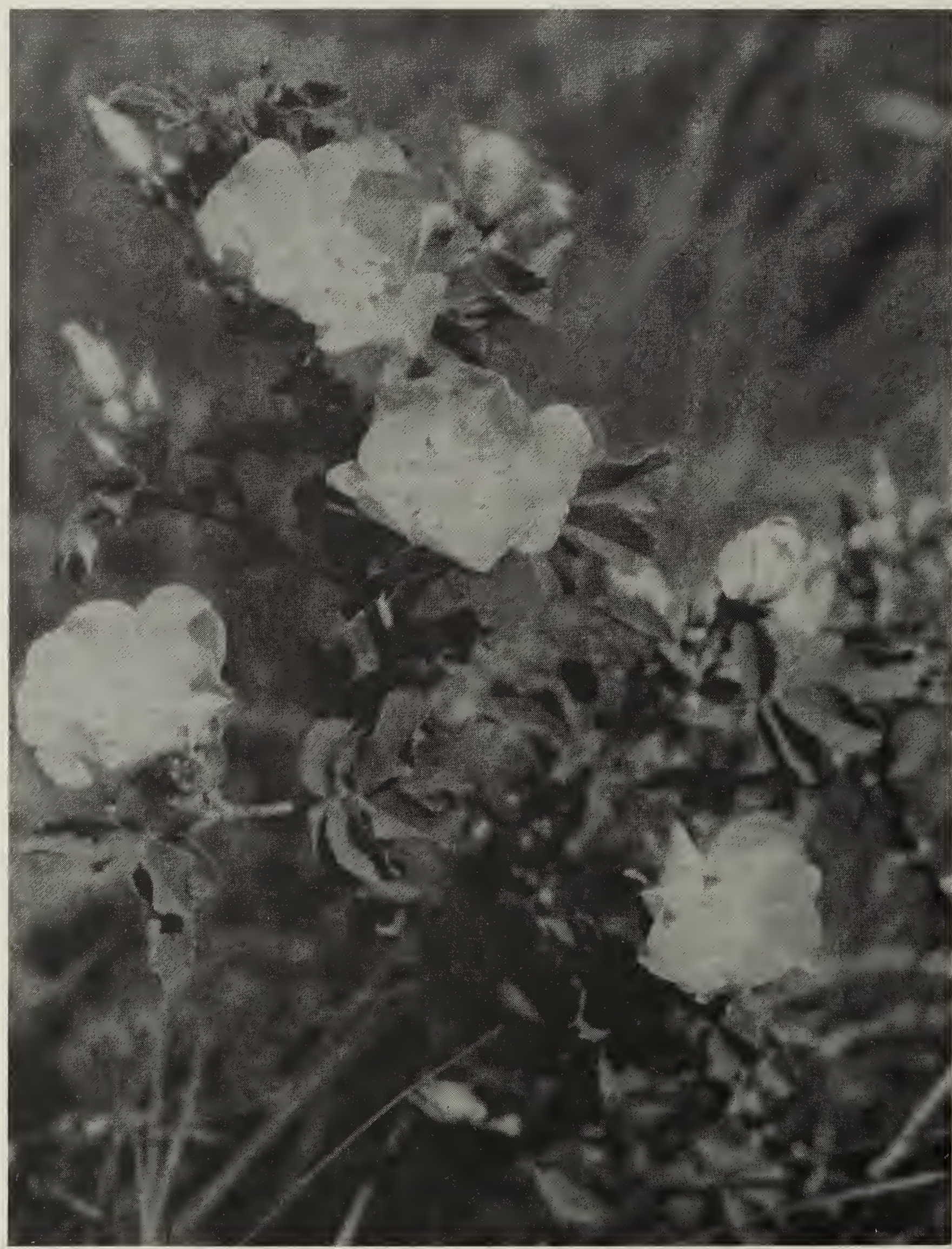

